Original Article

\title{
Knowledge of Nursing Students Regarding Housing Characteristics and Its Evaluation
}

Arif Ali, Abdur Rasheed, Fauzia Imtiaz, Mudassir Hussain, Muhammad Arsalan

Dow University of Health Sciences

Corresponding Author: arif_ali79@hotmail.com

\section{Abstract}

Objective The purpose of this research study is to assess the knowledge of housing characteristics and associated health problems in nursing students of Dow University of Health Sciences (DUHS). Moreover, nursing students' knowledge about housing condition and public health risks were also analyzed. Methodology The study was conducted at Institute of Nursing, DUHS, Karachi. In 2012, 90 nursing students were asked to participate in this study with their consents. A teaching session was conducted as a part of this study that lasted for two hours. At the end of teaching session students were requested to fill out the questionnaire about their housing condition and health related problems along with a feedback of the session. Results The study highlighted that on average, participants had been living in the same housing for the last one year, with median and inter-quartile range of 12 and 16 months respectively. Twelve participants (13\%) mentioned that they had suffered from diarrhea or vomiting during last three months, and $7.6 \%$ participants reported that their housing conditions were affecting their respiratory health. A large number of participants $(89.1 \%)$ and $(87.2 \%)$ did not find any visible mold in their house/hostel or kitchen respectively. Almost $61 \%$ and $80 \%$ participants reported about the mechanical ventilation and window in the bathroom respectively. Conclusion Reduction in dampness results in improvement of various health symptoms. House dust mite can be controlled through constant mechanical ventilation. The majority of the participants showed willingness towards such seminars and discussions for their future classes.

\section{Keywords}

Housing characteristics, dampness, mold, respiratory illness, nursing students.

\section{Introduction}

Housing is a vital element of health and inadequate housing is a foremost public health issue which is unexplored in nursing literature ${ }^{1}$. In the United States, every year 2900 people die in house fires ${ }^{2}$ and approximately, 2 million people, annually, visit hospitals because of symptoms related to asthma ${ }^{3}$.

In recent years, consciousness towards social elements of health including housing has grown increasingly ${ }^{4}$ However, determining what should be the role of the public health practitioner that influence housing characteristics is still challenging. An extensive literature searches exhibits that because of environmental hazards, the inadequate housing condition can directly contribute to infectious disease transmission, lead poisoning, asthma and other mental health problems $5,6,7,8$.

Inadequate housing features: unavailability of safe water for drinking, inappropriate ventilation system, mold in kitchen and bathroom. These have been recognized as causes of spread of infectious diseases ${ }^{9,10}$. It has also been identified that crowding is associated with tuberculosis transmission ${ }^{11}$ and respiratory infections ${ }^{12,13}$. Furthermore, 
different epidemiological studies have associated inadequate housing characteristics with risk of chronic diseases and few studies exhibited that dampness and moldy housing is linked with asthma and respiratory indications ${ }^{14,15,16,17}$. The use of toxic substance in houses may produce chronic health complications. Few research studies developed the association of passive tobacco smoking with respiratory diseases $^{18,19}$.

The primarily goal of research in nursing is to advance the quality of care by delivering the knowledge for practice ${ }^{20}$. This article seeks to make nurses more aware of housing strategy and emphasizes the negative health consequences that have been associated with it. The purpose of this research study is to assess housing characteristics of nursing students of DUHS along with associated health problems and respiratory infections if any. Moreover, nursing students' knowledge about housing condition and public health risks were also analyzed.

\section{Methodology}

\section{Setting and sample}

This research study was conducted at Dow University of Health Sciences (DUHS), Institute of Nursing in Karachi, where undergraduate and postgraduate programs are being taught. In 2012, 90 nursing students (undergraduate level) were approached and asked to participate in this research; all students showed their willingness and gave their consents of participation.

\section{Ethical Consideration}

An ethical report was also obtained by Institutional Review board from the institute to conduct the study as it involved the human subjects. IRB No. Ref. No: DUHS/DR/2010-74.

\section{Measurement and Instrument}

A standard questionnaire on housing condition and health was designed by public health course instructors. This questionnaire was first used in March 2007 and after minor revisions was used in March 2008 in the study ${ }^{21}$. We used this questionnaire in our study to assess the housing characteristics of nursing students of Dow University of Health Sciences, Karachi. The questionnaire was based on two parts; housing condition and participants' respiratory health.

The first part of this questionnaire included the questions regarding the Health and Housing Index (HHI) that was established to record the housing conditions pertaining to health and safety. The HHI questionnaire piloted in the study of Keall et al. ${ }^{22}$ on 100 homes. For this research study we extracted questions pertained to housing environment like questions on ventilation, mold, damp and usual house conditions. Nursing students were requested to complete 42 questions having multiple possible answer choices. As an example of typical question: how would you describe the ventilation of your house? Minimal (too little), Adequate or excessive (too much). The second part was based on questions regarding respiratory health related to those employed in the International Study of Asthma and Allergies in Childhood ${ }^{23}$. For example: have you woken up with an attack of shortness of breath at any time in the last 3 months? Yes, no or don't know.

\section{Data collection procedure}

A two hours long teaching session was conducted as a part of this study. That teaching session was based on educating participants on housing characteristics and associated respiratory health. Students were educated about the ideal and poor housing environment and its effect on health. Participants also discussed the basic aim of 
public health and in-house impact of social, biological, physical and chemical factors affecting on health. The instructors talked about the infectious disease transmission, asthma, diarrhea, vomiting and headache symptoms caused by inadequate housing condition.

Every participant, at the end of the teaching session, was requested to fill out the questionnaire about housing condition and respiratory health. Through this questionnaire, the knowledge regarding impact of social, biological, physical and chemical factors was assessed. Furthermore, feedback of the session was also obtained on a separate session questionnaire containing 10 questions. Participants were requested to rate the value of the session on the Likert scale. Feedback questionnaire was based on questions about how much this session and discussion improved your understanding regarding public health, epidemiology and environmental elements of health, as well as, whether this session simulate participant to discuss housing characteristics and the health issue with their colleagues.

\section{Data analysis}

Data were entered in and analyzed with SPSS version 21.0. Continuous variables were presented through median and interquartile range and all categorical variables were presented through frequencies and percentages.

\section{Results}

It was found that the majority of the nursing students $(69.6 \%)$ live with parents, $23.9 \%$ residing in rented houses and only $6.5 \%$ live in hostel/hall of residence. The most common language of nursing students was Urdu as there were $42.4 \%$ participants who spoke Urdu, whereas, other common languages were Sindhi and Pashto 27.2\% and $13.0 \%$ respectively. The rate of smoking among participants were very low only 4.3 $\%$ smoked one or more cigarettes per day and only $5.4 \%$ mentioned that other family member smoked cigarettes inside the house.

Table 1 exhibits, descriptive statistics of house structure and family members (including study participants) were living in the house. It was noted that on average participants have been living for the last one year where they are now; with median and inter-quartile range of 12 and 16 months respectively. Data revels that on average (median) there were 3.5 adults (age $\geq 18$ ) and one child (age $<18$ ) in each participant's house. Furthermore, data did not reveal the trend of high-rise building residence among nursing students as the average (median) participants were living in single story houses.

It has been noted that out of 90 participants only two had wheezing chest at any time for the last three months. Those two participants had also been medically diagnosed as having asthma and they were also taking medicine (including inhalers, aerosols or tablets).

Twelve participants (13\%) mentioned that they had suffered from diarrhea or vomiting during last three months, while headache was found in the majority of the participants $(68.5 \%)$. Few participants $(7.6 \%)$ reported that their housing condition was affecting their respiratory health.

While giving opinion regarding sleep quality, the majority of the participants $(93.5 \%)$ reported that their sleep was affected by bedbugs. Moreover, according to $62 \%$ participants overcrowding was the reason of mental disturbance and $37 \%$ felt that due to poor ventilation they were disturbed mentally.

Figure 1 describes knowledge of nursing students regarding different physical, chemical, biological and social factors 
affecting on the health inside houses. It is apparent that $17.4 \%$ participants felt that their health affected due improper ventilation system and very few (3.3\%) felt that temperature was the problem; however, the majority $(79.3 \%)$ felt that both unsuitable ventilation system and temperature badly affected their health. Many participants (67.4\%) gave their opinion about chemical factors that fuel materials, insecticides, medicines and burnt gases together affecting their houses. A similar pattern was observed for biological and social factors.

Table 2 exhibits that majority of participants $(60.5 \%)$ lived in well-maintained buildings and very few $(5.8 \%)$ lived in poorly maintained buildings. Sixty-five percent participants felt no dampness at their houses, whereas $10.5 \%$ felt dampness throughout. The Diversity of ventilation description was observed, $44.2 \%$ participants reported that they had adequate ventilation at their houses while, $37.2 \%$ mentioned that they had excessive ventilation and according to $18.6 \%$ there were too little ventilation. Furthermore, many participants $(87.2 \%)$ reported that they had natural ventilation (One or more open able window, or window vents) in the kitchen and just more than half participant $(55.8 \%)$ indicated the existence of mechanical ventilation in the kitchen. A Large number of participants $(89.1 \%)$ and $(87.2 \%)$ did not find any visible mold at house/hostel and kitchen respectively.
Almost $61 \%$ and $80 \%$ participants reported about the mechanical ventilation and window in the bathroom respectively. Nearly every participant $(95.7 \%)$ mentioned that they used some form of heating to heat their houses or hostel.

From table 3, it is quite obvious that overall positive response was obtained, because $71.4 \%$ nursing student greatly support or support (score 1 and 2) the use of survey and seminar discussion for their future classes. The majority of the nursing students $(78.3 \%)$ felt that they had improved their understanding of environmental health determinants and only $1.1 \%$ participants felt that they did not improve at all. For the question asking if this survey and seminar discussion improve the interest in public health; $68.4 \%$ nursing students responded yes it improved their interest in public health and only $4.3 \%$ participants felt that this seminar did not improve their interest in public health. Moreover, most of the nursing student $(76.1 \%)$ felt that through this survey and seminar their interest in health research had improved and again for few participant $(4.3 \%)$ their interest had not improved at all and $13 \%$ participants were neutral (score 3 ). It is interesting to know that this survey simulated $70.7 \%$ nursing students to discuss housing and health issues with friends outside the class and $21.7 \%$ were neutral about simulation through this survey. 


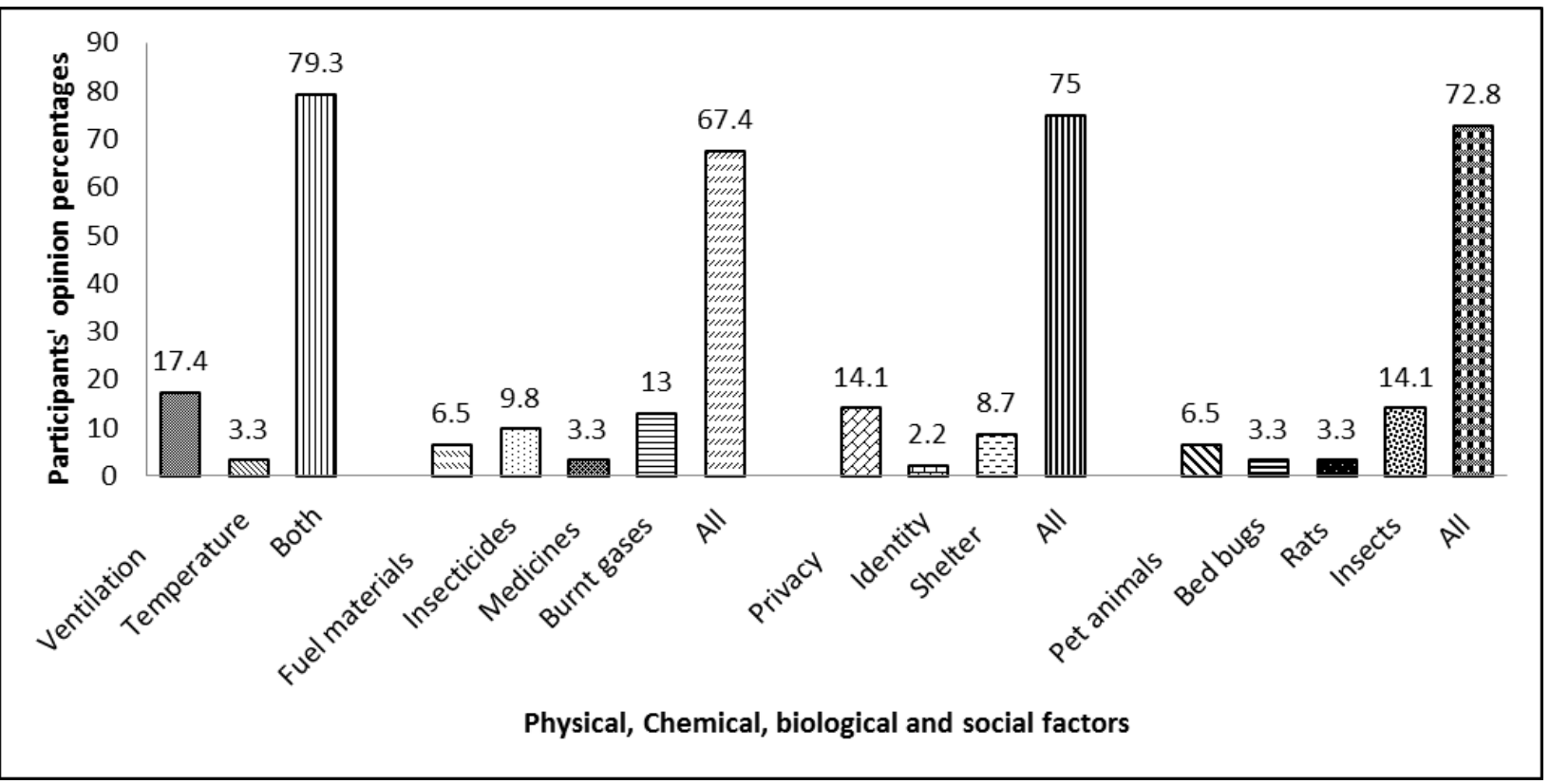

Figure 1: Knowledge regarding physical, chemical, biological and social factor affecting on health inside the houses

Table 1: House structure and people living in house

\begin{tabular}{lcc}
\multicolumn{1}{c}{ Questions } & Median & $\begin{array}{c}\text { Inter-quartile } \\
\text { range }\end{array}$ \\
\hline How long (in months) have you lived where you are now? & 12 & 16 \\
$\begin{array}{l}\text { How many adults (age } \geq 18 \text { ) usually live in your house } \\
\text { (include yourself)? }\end{array}$ & 3.5 & 2 \\
How many couples usually live in your house? & 1 & 1 \\
How many children (age <18) usually live in your house? & 1 & 2 \\
How many stories have the house/block? & 1 & 3 \\
How many bedrooms are there in the house? & 3 & 2 \\
\hline
\end{tabular}

Table 2: Housing characteristics

\begin{tabular}{|l|c|}
\hline \multicolumn{1}{|c|}{ Generally, the building is? } & n (\%) \\
\hline Well maintained & $52(60.5)$ \\
\hline Reasonably maintained & $29(33.7)$ \\
\hline Poorly maintained Subjective 'dampness' feel of house? & $5(5.8)$ \\
\hline \multicolumn{1}{|c|}{ Does the house smell 'musty'? } \\
\hline Feels dry throughout & $52(60.5)$ \\
\hline Feels damp in places & $25(29.1)$ \\
\hline Feels damp throughout & $9(10.5)$ \\
\hline Yes & $9(10.5)$ \\
\hline No & $77(89.5)$ \\
\hline
\end{tabular}




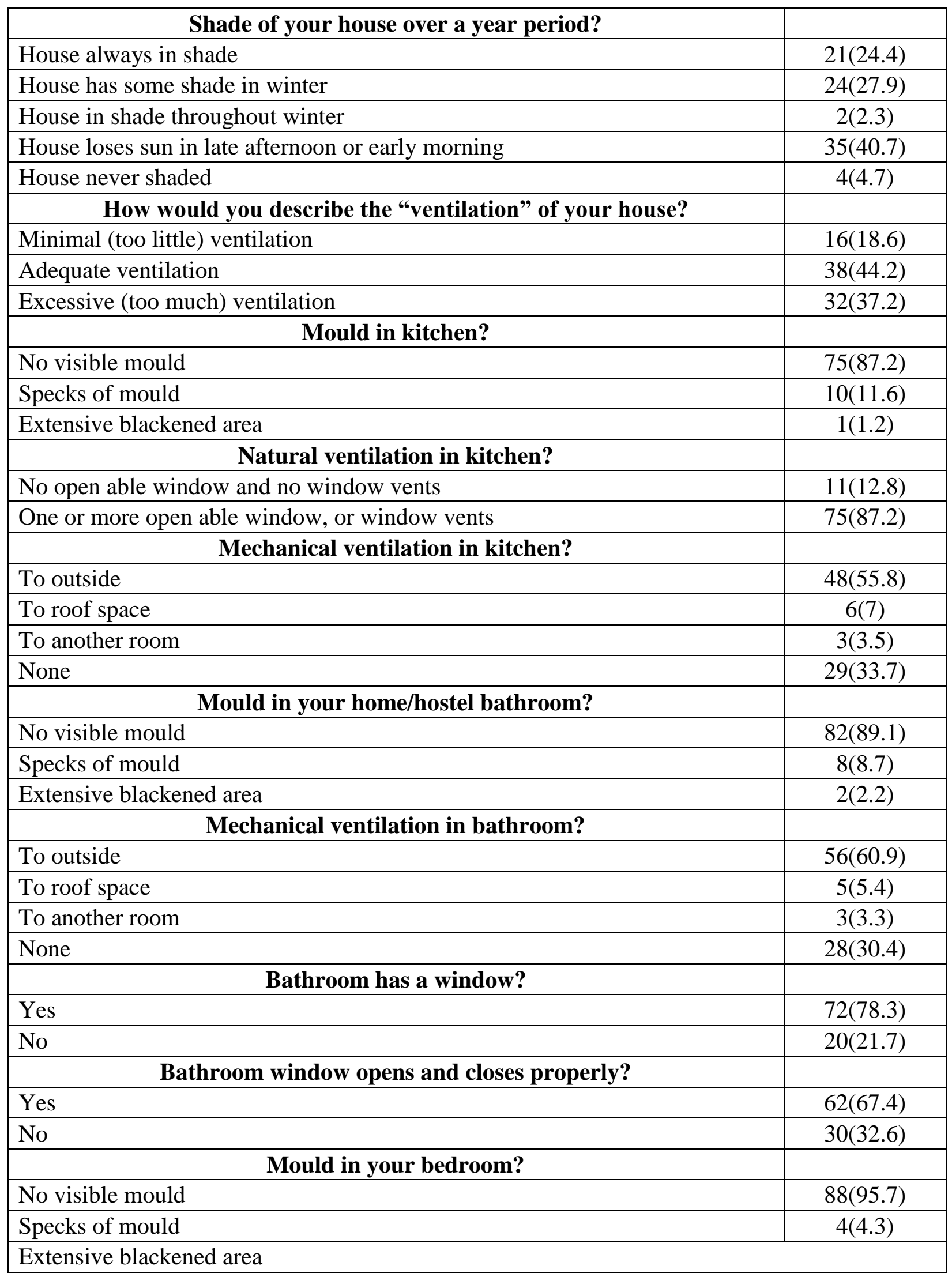




\begin{tabular}{|l|c|}
\hline \multicolumn{1}{|c|}{ Is your bedroom the mouldiest room of the house/hostel? } & \\
\hline Yes Weather-tightness of roof and windows? & $22(23.9)$ \\
\hline No & $70(76.1)$ \\
\hline Weather-tight & $65(70.7)$ \\
\hline Moderate leaks & $25(27.2)$ \\
\hline Extensive leaks & $2(2.2)$ \\
\hline \multicolumn{1}{|c|}{ Ceiling insulation? } & $31(33.7)$ \\
\hline Yes & $42(45.7)$ \\
\hline No you use any form of heating to heat your house/hostel? & $19(20.7)$ \\
\hline Yes Know & $88(95.7)$ \\
\hline No & $4(4.3)$ \\
\hline
\end{tabular}

Table 3: Results of nursing student feedback on the value of housing conditions and respiratory health teaching exercise $(n=92)$

\begin{tabular}{|c|c|c|c|c|c|c|c|}
\hline \multirow{3}{*}{\begin{tabular}{l}
\multicolumn{1}{c}{ Questions } \\
How valuable \\
has the student \\
housing \\
conditions \\
survey, and \\
discussion of \\
findings, been \\
for you?
\end{tabular}} & \multicolumn{7}{|c|}{ Likert Scale } \\
\hline & $\begin{array}{l}\text { Extremely } \\
\text { valuable }\end{array}$ & 1 & 2 & 3 & 4 & 5 & $\begin{array}{c}\text { Not at all } \\
\text { valuable }\end{array}$ \\
\hline & No. $(\%)$ & $44(47.8)$ & $22(23.9)$ & $22(23.9)$ & $2(2.2)$ & $2(2.2)$ & \\
\hline \multirow[b]{2}{*}{$\begin{array}{l}\text { Did this } \\
\text { survey and } \\
\text { seminar } \\
\text { discussion } \\
\text { improve } \\
\text { your } \\
\text { understanding } \\
\text { of research } \\
\text { methods? }\end{array}$} & Yes, greatly & 1 & 2 & 3 & 4 & 5 & No, not at all \\
\hline & No. (\%) & $47(51.1)$ & $23(25.0)$ & $16(17.4)$ & $5(5.4)$ & $1(1.1)$ & \\
\hline \multirow{3}{*}{$\begin{array}{l}\text { Did this } \\
\text { survey and } \\
\text { seminar } \\
\text { discussion } \\
\text { improve your } \\
\text { understanding } \\
\text { of } \\
\text { epidemiology? } \\
\text { Did this }\end{array}$} & Yes, greatly & 1 & 2 & $\mathbf{3}$ & 4 & 5 & No, not at all \\
\hline & No. (\%) & $42(45.7)$ & $22(23.9)$ & $14(15.2)$ & $5(5.4)$ & $9(9.8)$ & \\
\hline & Yes, greatly & 1 & 2 & 3 & 4 & 5 & No, not at all \\
\hline
\end{tabular}




\begin{tabular}{|c|c|c|c|c|c|c|c|}
\hline $\begin{array}{l}\text { survey and } \\
\text { seminar } \\
\text { discussion } \\
\text { improve your } \\
\text { understanding } \\
\text { of the } \\
\text { environmental } \\
\text { determinants } \\
\text { of health? }\end{array}$ & No. (\%) & $48(52.2)$ & $24(26.1)$ & $13(14.1)$ & $6(6.5)$ & $1(1.1)$ & \\
\hline \multirow[b]{2}{*}{$\begin{array}{l}\text { Did this } \\
\text { survey and } \\
\text { seminar } \\
\text { discussion } \\
\text { improve your } \\
\text { interest in } \\
\text { public health? }\end{array}$} & Yes, greatly & 1 & 2 & 3 & 4 & 5 & No, not at all \\
\hline & No. $(\%)$ & $36(39.1)$ & $27(29.3)$ & $24(26.1)$ & $1(1.1)$ & $4(4.3)$ & \\
\hline \multirow[b]{2}{*}{$\begin{array}{l}\text { Did this } \\
\text { survey and } \\
\text { seminar } \\
\text { discussion } \\
\text { improve your } \\
\text { interest in } \\
\text { health } \\
\text { research? }\end{array}$} & Yes, greatly & 1 & 2 & 3 & 4 & 5 & No, not at all \\
\hline & No. $(\%)$ & $44(47.8)$ & $26(28.3)$ & $12(13.0)$ & $6(6.5)$ & $4(4.3)$ & \\
\hline \multirow[b]{2}{*}{$\begin{array}{l}\text { Did this } \\
\text { survey } \\
\text { stimulate you } \\
\text { to discuss } \\
\text { housing and } \\
\text { health issues } \\
\text { with friends } \\
\text { outside of } \\
\text { class? }\end{array}$} & Yes, greatly & 1 & 2 & 3 & 4 & 5 & No, never \\
\hline & No. $(\%)$ & $39(42.4)$ & $26(28.3)$ & $20(21.7)$ & $6(6.5)$ & $1(1.1)$ & \\
\hline \multirow[b]{2}{*}{$\begin{array}{l}\text { How much did } \\
\text { this survey and } \\
\text { seminar } \\
\text { discussion } \\
\text { challenge you } \\
\text { to think? }\end{array}$} & Yes, greatly & 1 & 2 & 3 & 4 & 5 & Very little \\
\hline & No. (\%) & $33(35.9)$ & $29(31.5)$ & $19(20.7)$ & $6(6.5)$ & $5(5.4)$ & \\
\hline \multirow[b]{2}{*}{$\begin{array}{l}\text { Has this } \\
\text { survey and } \\
\text { seminar } \\
\text { discussion } \\
\text { made you } \\
\text { more aware } \\
\text { and concerned }\end{array}$} & Yes, greatly & 1 & 2 & 3 & 4 & 5 & No, not at all \\
\hline & No. $(\%)$ & $33(35.9)$ & $24(26.1)$ & $27(29.3)$ & $6(6.5)$ & $2(2.2)$ & \\
\hline
\end{tabular}




\begin{tabular}{|l|l|l|l|l|l|l|l|}
\hline $\begin{array}{l}\text { about societal } \\
\text { problems? }\end{array}$ & & & & & & \\
\hline $\begin{array}{l}\text { Would you } \\
\text { support use of } \\
\text { this survey and } \\
\text { seminar } \\
\text { discussion for } \\
\text { future year } \\
\text { classes? }\end{array}$ & Yes, greatly & $\mathbf{1}$ & $\mathbf{2}$ & $\mathbf{3}$ & $\mathbf{4}$ & $\mathbf{5}$ & No, not at all \\
\cline { 2 - 8 } & No. (\%) & $48(52.7)$ & $17(18.7)$ & $14(15.4)$ & $4(4.4)$ & $8(8.8)$ & \\
\hline
\end{tabular}

\section{Discussion}

It was found that only two nursing students have respiratory symptoms associated with housing conditions, and according to only $7.6 \%$ nursing students their respiratory health was being affected by their housing conditions. Therefore, as far as respiratory health is concerned, findings shows that the housing characteristics of nursing students of Dow University of Health Sciences is not of serious concern because data did not show that several nursing students are being affected by respiratory problems.

Different research studies have linked dampness and cold housing with respiratory complaint ${ }^{24,25,26}$ but in this research study we could not identify any association of respiratory problems with housing condition because of small sample size, and therefore, only two such participants were found.

Twenty-nine per cent of nursing students reported that there was dampness in places at homes. Though, this figure is not much different from the study of Butler et $\mathrm{al}^{27}$, and in line with international findings that exhibit dampness rate varying from $30-37 \%$ in Canada and Great Britain ${ }^{16,24}$. We found that almost all nursing students (95.7\%) used some form of heating system in their house that is in agreement of several authors' proposal that reduction in dampness in the house, would help to alleviate symptoms of poor health $^{28,17}$.
Descriptive statistics reinforce the findings that we have obtained as highly valuable and positive feedback regarding the teaching sessions that was conducted as an integrated part of the study. This positive attitude of nursing students shows the importance of the teaching session and what they learnt could apply in their daily life to make their housing characteristic much better. Nearly three fourth of the nursing students showed their support and willingness about the arrangements of such seminars and discussions for their future classes.

Further research is recommended with larger sample size to establish some association with respiratory illness and dampness/mold. It is important to initiate some strategies against respiratory diseases, as it has profound social burden and cost on society.

\section{Conclusion}

Reduction in dampness results alleviation of inadequate health symptoms. House dust mite can be controlled; trough continues mechanical ventilation. Overcrowding and poor ventilation have profound effect on mental health. In this study, we found that the majority of the nursing students answered favorably to such seminar and discussion, and they felt that provision of knowledge about housing characteristics should continue for their future classes.

Acknowledgement

N/A 
Conflict of Interest

N/A

\section{References}

1. Sharfstein, Joshua, \& Sandel, Megan. (1998). Not safe at home: how America's housing crisis threatens the health of its children. Boston: Boston University Medical Center.

2. Karter, Michael J. (2000). Fire loss in the United States during 1999: National Fire Protection Association.

3. McCaig, Linda F, \& Burt, Catharine W. (2001). National hospital ambulatory medical care survey: 1999 emergency department summary: Department of Health and Human Services, Centers for Disease Control and Prevention, National Center for Health Statistics.

4. Marmot, Michael, \& Wilkinson, Richard. (2005). Social determinants of health: Oxford University Press.

5. Evans, Gary W, Wells, Nancy M, Chan, Hoi-Yan Erica, \& Saltzman, Heidi. (2000). Housing quality and mental health. Journal of consulting and clinical psychology, 68(3), 526.

6. Fuller-Thomson, Esme, Hulchanski, J David, \& Hwang, Stephen. (2000). The housing/health relationship: what do we know? Reviews on environmental health, 15(1-2), 109-134.

7. Krieger, James, \& Higgins, Donna L. (2002). Housing and health: time again for public health action. American journal of public health, 92(5), 758-768.

8. Matte, Thomas D, \& Jacobs, David E. (2000). Housing and health-current issues and implications for research and programs. Journal of Urban Health, 77(1), 7-25.

9. Marsh, Boyd T. (1981). Housing and health. The role of the environmental health practitioner. Journal of environmental health, 45(3), 123-128.

10. Mood, ERIC W. (1993). Fundamentals of healthful housing: their application in the 21st century. 1993) Unhealthy housing: research, remedies and reforms. London, $E \&$ FN Spon.

11. Stein, Lilli. (1950). A Study of Respiratory Tuberculosis in Relation to Housing Conditions in Edinburgh I.The Pre-War Period. British journal of social medicine, 4(3), 143-169.

12. Denny Jr, Floyd W. (1995). The clinical impact of human respiratory virus infections. American journal of respiratory and critical care medicine, 152(4), S4.

13. Graham, Neil M. (1989). The epidemiology of acute respiratory infections in children and adults: a global perspective. Epidemiologic reviews, 12, 149-178.

14. Bornehag, Carl-Gustaf, Blomquist, G, Gyntelberg, F, Jarvholm, B, Malmberg, P, Nordvall, L, . . . Sundell, Jan. (2001). Dampness in buildings and health. Indoor air, 11(2), 72-86.

15. Peat, Jennifer K, Dickerson, J, \& Li, J. (1998). Effects of damp and mould in the home on respiratory health: a review of the literature. Allergy, 53(2), 120-128.

16. Platt, Stephen D, Martin, Claudia J, Hunt, Sonja M, \& Lewis, Chris W. (1989). Damp housing, mould growth, and symptomatic health state. Bmj, 298(6689), 1673-1678.

17. Williamson, IJ, Martin, CJ, McGill, G, Monie, RD, \& Fennerty, AG. (1997). Damp housing and asthma: a case-control study. Thorax, 52(3), 229-234.

18. Cook, Derek G, \& Strachan, David P. (1997). Health effects of passive smoking. 3. Parental smoking and 
prevalence of respiratory symptoms and asthma in school age children. Thorax, 52(12), 1081-1094.

19. Weitzman, Michael, Gortmaker, Steven, Walker, Deborah Klein, \& Sobol, Arthur. (1990). Maternal smoking and childhood asthma. Pediatrics, 85(4), 505-511.

20. Rodgers, Sheila. (1994). An exploratory study of research utilization by nurses in general medical and surgical wards. Journal of Advanced Nursing, 20(5), 904911.

21. Millar, Elinor, Baker, Michael G, Howden-Chapman, Philippa, Wilson, Nick, \& Dickson, Nigel. (2009). Involving students in real-world research: a pilot study for teaching public health and research skills. BMC medical education, 9(1), 45.

22. Keall, Michael D, Baker, Michael, Howden-Chapman, Philippa, \& Cunningham, Malcolm. (2008). Association between the number of home injury hazards and home injury. Accident Analysis \& Prevention, 40(3), 887-893.

23. Asher, MI, Keil, Ulrich, Anderson, HR, Beasley, R, Crane, J, Martinez, F, . . . Stewart, AW. (1995). International Study of Asthma and Allergies in Childhood (ISAAC): rationale and methods.
European respiratory journal, 8(3), 483491.

24. Dales, Robert E, Zwanenburg, Harry, Burnett, Richard, \& Franklin, Claire A. (1991). Respiratory health effects of home dampness and molds among Canadian children. American journal of epidemiology, 134(2), 196-203.

25. Evans, Julie, Hyndman, Sophie, StewartBrown, Sarah, Smith, David, \& Petersen, Sophie. (2000). An epidemiological study of the relative importance of damp housing in relation to adult health. Journal of Epidemiology and Community Health, 54(9), 677-686. doi: http://dx.doi.org/10.1136/jech.54.9.677

26. Hopton, Jane L, \& Hunt, Sonja M. (1996). Housing conditions and mental health in a disadvantaged area in Scotland. Journal of Epidemiology and Community Health, 50(1), 56-61.

27. Butler, Sarnia, Williams, Maynard, Tukuitonga, Colin, \& Paterson, Janis. (2003). Problems with damp and cold housing among Pacific families in New Zealand.

28. Hyndman, SJ. Housing dampness and health amongst British Bengalis in East London. Social Science \& Medicine,1990; 30(1), 131-141. 